\title{
Development and Evaluation of Cinnarizine Loaded Nanosponges: Pharmacodynamic and Pharmacokinetic Study on Wistar Rats
}

\author{
${ }^{1}$ Madhuri Dinde*, ${ }^{2}$ Upendra Galgatte, ${ }^{3}$ Firdous Shaikh \\ ${ }^{1}$ Department of Pharmaceutics, ${ }^{2}$ Department of Pharmaceutics, ${ }^{3}$ Department of Pharmaceutics \\ ${ }^{1}$ GES's Satara College of Pharmacy, Satara, (Maharashtra) India, 2P.E.S's Modern College of Pharmacy, Nigdi, Pune (Maharashtra) India, \\ ${ }^{3}$ GES's Satara College of Pharmacy, Satara (Maharashtra) India. \\ *Corresponding author's E-mail: sakshamelectricals@gmail.com
}

Received: 18-09-2020; Revised: 24-11-2020; Accepted: 02-12-2020; Published on: 15-12-2020. \begin{abstract}
The purpose of this study research was to improve bioavailability of Cinnarizine, a poorly water-soluble drug. The objective of this study is to formulate and evaluate Cinnarizine loaded nanosponges to increases the bioavailability of cinnarizine. Cinnarizine loaded nanosponges were prepared by quasi emulsion solvent diffusion method. The drug loaded nanosponge was characterized by FTIR, DSC, PXRD and SEM. Cinnarizine was loaded by using Eudragit RS 100, cold polyvinyl alcohol, dichloromethane, and distilled water. The prepared nanosponges were formulated and evaluated for powder properties, Pharmacodynamic and pharmacokinetic studies. Cinnarizine loaded nanosponges were white in color and odorless. FTIR study of formulation has shown that there were no interactions between drug and other excipients. X-ray diffraction (XRD) study of formulation confirmed amorphous nature of cinnarizine. For optimized batch (F5), percent yield $(60.89 \pm 0.18 \%)$, entrapment efficiency $(70.85 \pm 0.41 \%)$, particle size $(492.33 \mathrm{~nm})$, Polydispersity index $(0.08103 \pm 0.04)$, zeta potential $(5.67 \mathrm{mV})$, drug content $(82.88 \pm 0.88 \%)$. Stability study of nanosponge was carried out as per ICH guidelines. The results of in vivo studies showed 1.4 times increases in bioavailability of Cinnarizine by nanosponges as compared to pure Cinnarizine powder. It was possible to prepare nanosponges of Cinnarizine by using quasi emulsion solvent diffusion method to obtain the best possible formulation.
\end{abstract}

Keywords: Eudragit RS 100, polyvinyl alcohol, Cinnarizine, nanosponges, Quassi emulsion solvent diffusion.

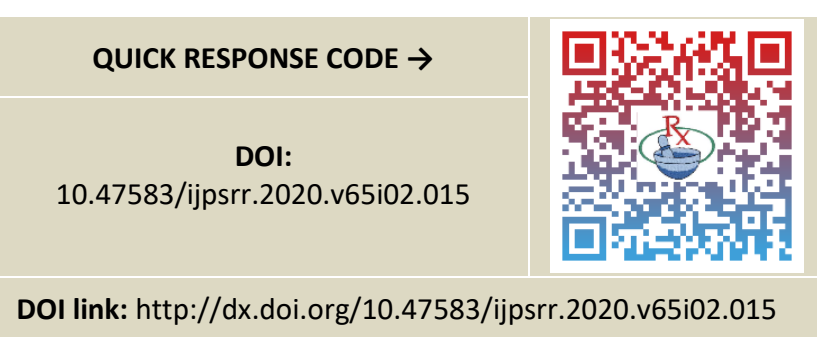

\section{INTRODUCTION}

ow aqueous solubility of drug has always presented major obstacle towards the development of drug delivery systems which often compromises patient compliance. Oral route is thought to be common and easy for drug administration. On oral administration of drug in its dosage form, it is expected to dissolve and release the drug into the gastrointestinal fluid before the absorption. Poor solubility may limit the dissolution of drug in gastrointestinal tract resulting to low bioavailability that can pharmacologically affect the therapeutic efficacy of drug. ${ }^{1}$ The drugs belonging to BCS class II particularly fall in this category and have been extensively researched molecular optimization and development of novel efficacious dosage forms. Cinnarizine, (E)-1(diphenylmethyl)-4-(3-phenylprop-2-enyl) piperazine, having molecular formula $\mathrm{C}_{26} \mathrm{H}_{28} \mathrm{~N}_{2}$ and molecular weight $368.51 \mathrm{~g} / \mathrm{mol}$, is white or almost white powder. It is originally obtained from wood-reed roots (Cinna). It is a weak base with poor aqueous solubility. ${ }^{2}$ Nanosponges are porous polymeric delivery systems that are small spherical particles with large porous surface. A sponge that has nano size holes, especially one used for bio-mimetic detoxification. The sponge acts as a three-dimensional network or scaffold, which consist of the backbone known as long-length polyester. ${ }^{3}$ Oral drug delivery has long been a problem for medical researchers how to get them to the right place in the body and how to control the release of the drug to prevent overdose. The development of new and complex molecules called nanosponges has the potential to solve these problems. Nanosponge is a novel and emerging technology which play a vital role in targeting drug delivery in a controlled manner. A wide variety of drugs can be loaded into nanosponge for oral drug delivery. These particles are capable of carrying both lipophilic and hydrophilic substances and of improving the solubility of poor water soluble molecule like cinnarizine. Nanosponges are small size and porous nature they can bind poorly soluble drugs within their matrix and improve their bioavailability. Cinnarizine is more commonly prescribed for nausea and vomiting due to motion sickness. Cinnarizine used in chemotherapy, vertigo or Meniere's disease. It is given in lower dose $25 \mathrm{mg} \& 75 \mathrm{mg}$ higher doses of Cinnarizine. It can be taken by adults and by children over 5 years of age. Cinnarizine is used to treat problems affecting the inner ear and balance such as dizziness and sickness. It is also helpful in preventing travel sickness. There is a need to minimize the dose, avoid repetition of dosing frequency and minimize the side effects. Thus, there is a need to increase the efficacy of Cinnarizine. Formulating vesicular carriers like 
nanosponges because nanosponges are more stable than other vesicular carrier system. ${ }^{4}$

In this study attempt has been carried out to improve the bioavailability of Cinnarizine (CN) by formulating it in the form of nanosponges; otherwise, its use would be limited due to poor aqueous solubility.

\section{MATERIALS AND METHODS}

\section{Materials}

Cinnarizine (CN) was provided as gift sample from Wallance Pharmaceuticals (Goa, India). Eudragit RS 100 was obtained from Analab fine chemicals (Mumbai, India), dichloromethane, polyvinyl alcohol, hydrochloric acid was supplied by Loba Chemicals (Mumbai, India). Gum arabic and hydrated aluminium silicate (Kaolin) was kindly supplied by Merck chemicals.

\section{Formulation and optimization}

\section{Formulation of cinnarizine loaded nanosponge}

The inner phase was prepared by using Eudragit RS 100 and dichloromethane (extra pure); Eudragit RS 100 (150 $\mathrm{mg}$ ) was completely dissolved in dichloromethane $(10 \mathrm{ml})$ with continuous stirring. The outer phase was prepared by using cold polyvinyl alcohol and distilled water. Using magnetic stirrer, (cold) PVA (40 mg) was dissolved in distilled water. Cinnarizine $(25 \mathrm{mg})$ was added in inner phase, using ultra probe sonicator for 5-6 cycles (Time for one cycle=20sec). After adding inner phase into outer phase, a mixture formed was placed up to $3 \mathrm{hrs}$ on magnetic stirrer, without heating. Magnetic stirring speed was kept $2000 \mathrm{rpm}$. Beaker containing formulation was kept in water bath, at $60^{\circ} \mathrm{C}$ then final formulation was obtained. $5,6,7$

\section{Design of experiment}

Optimization of $3^{2}$ factorial design of experiment was followed with 3 levels and 2 factors and runs 9 batches using the Design Expert software (version 8) was generated for the experimental design of Cinnarizine loaded nanosponges. According to $3^{2}$ full factorial designs, possible combinations are mentioned in Table 1 . The amount of nanosponges forming polymer, Eudragit RS 100 $\left(X_{1}\right)$ and cold PVA $\left(X_{2}\right)$, were independent variables and entrapment efficiency, particle size, percent yield, drug release, zeta potential were dependent variables. Two independent factors, the concentrations of Eudragit RS 100 and (cold) PVA were chosen at low, medium and high levels.

Table 1: Optimization by $3^{2}$ factorial Batches

\begin{tabular}{|c|c|c|c|c|c|c|c|c|c|c|}
\hline Sr. No & Ingredients & F1 & F2 & F3 & F4 & F5 & F6 & F7 & F8 & F9 \\
\hline 1 & CIN (mg) & 25 & 25 & 25 & 25 & 25 & 25 & 25 & 25 & 25 \\
\hline 2 & Eudragit RS 100(mg) & 100 & 100 & 100 & 150 & 150 & 150 & 200 & 200 & 200 \\
\hline 3 & Cold PVA(m) & 10 & 10 & 10 & 40 & 40 & 40 & 75 & 75 & 75 \\
\hline 4 & DCM (mL) & 10 & 10 & 10 & 10 & 10 & 10 & 10 & 10 & 10 \\
\hline 5 & Distilled water $(\mathrm{ml})$ & 10 & 10 & 10 & 10 & 10 & 10 & 10 & 10 & 10 \\
\hline
\end{tabular}

\section{Preformulation characterization}

\section{UV spectrum analysis of $C N$}

The solution of Cinnarizine was prepared in $0.1 \mathrm{~N} \mathrm{HCl}(\mathrm{pH}$ 1.2). The sample was scanned between $200-400 \mathrm{~nm}$ to obtain the maximum wavelength of absorption and UV spectrum by using blank $0.1 \mathrm{~N} \mathrm{HCl}$ of $\mathrm{pH} 1.2$.

\section{Standard plot of Cinnarizine in $0.1 \mathrm{~N} \mathrm{HCl}$}

Accurately weighed $10 \mathrm{mg}$ of Cinnarizine was added to $100 \mathrm{~mL}$ volumetric flask. Volume was made up to $100 \mathrm{~mL}$ with stock solution. From this, $0.2 \mathrm{~mL}$ was withdrawn and added into $10 \mathrm{~mL}$ volumetric flask and volume was adjusted up to mark with $0.1 \mathrm{~N} \mathrm{HCl} \mathrm{pH} 1.2(2 \mu \mathrm{g} / \mathrm{mL})$. Like this, from the stock solution $0.2,0.4,0.6,0.8,1.0,1.2,1.4 \mathrm{~mL}$ solution was withdrawn and added into volumetric flask of capacity $10 \mathrm{~mL}$ and finally diluted up to $10 \mathrm{~mL}$ with $0.1 \mathrm{~N} \mathrm{HCl}(\mathrm{pH} 1.2)$ to get the solutions with concentration of $2-14 \mu \mathrm{g} / \mathrm{mL}$ respectively. The absorbance was measured by UV-visible spectrophotometer for each solution at $253 \mathrm{~nm}$. 8, 9, 10

\section{Drug polymer compatibility study}

Three individual infrared spectra viz. Cinnarizine, Eudragit RS 100 and optimized formulation (F5) were recorded by Jasco M410 FTIR spectrophotometer. After baseline correction, the spectra of cinnarizine with potassium bromide, Eudragit RS 100 with potassium bromide and triturated nanosponges with potassium bromide were recorded. All samples were scanned from 4000 to $400 \mathrm{~cm}^{-}$ 1 and finally the drug-polymer compatibility was confirmed. ${ }^{11}$

\section{Differential Scanning Calorimetry (DSC)}

Cinnarizine loaded nanosponges (CLN) of the optimized batch was analyzed for thermal analysis by using differential scanning calorimerty. DSC measurement was performed on a differential scanning calorimetry equipped with an intra-cooler (DSC Mettler STAR SW 9.20, Switzerland). The analysis was carried out on a sample sealed in standard aluminum pans. An empty aluminum pan used as reference. Inert atmosphere was maintained by purging nitrogen gas at a flow rate of $25 \mathrm{ml} / \mathrm{min}$ at a scanning rate of $10^{\circ} \mathrm{C}$ per min from 50 to $300^{\circ} \mathrm{C} .{ }^{12}$ 


\section{Powder X-ray diffraction studies (PXRD)}

X-Ray diffraction (XRD) measurement of pure cinnarizine was performed by using Philips (PW 3710) Expertpro MPD Diffractometer (PAN analytical Inc, Germany) with resolution of $0.001 A^{\circ}$. The pure drug sample of $10 \mathrm{mg}$ was sprinkled on vacuum grease applied glass slide to make a layer having a thickness of $0.5 \mathrm{~mm}$ and slick the sample to slide before measurement. The samples were radiated using a Copper target tube. Scanning angles ranged from $5^{\circ}$ to $60^{\circ}$ of $2 \varnothing$. The current used was $40 \mathrm{~mA}$ and voltage 40kV. ${ }^{13}$

\section{Scanning electron microscopy (SEM)}

The detailed surface characteristics of the optimized batch of Cinnarizine particles were observed by using a JEOL Scanning electron Microscope (Model: JSM 6360 A, Japan).The samples were attached to the specimen holder to aluminum stab by using a double coated adhesive tape and gold coated (20 nm thickness) under vacuum using sputter coater (Model : IB -2, Hitachi, Tokyo, Japan) During gold coating process the samples were exposed to vacuum for 5-10 $\mathrm{min}$ at $40 \mathrm{~mA}$ and investigate a accelerating voltage of $15 \mathrm{kV}$ and $10 \mathrm{kV}$ was applied and the image was photographed by Asia Pentex Camera. ${ }^{14}$

\section{Formulation study}

\section{Determination of percentage yield}

The total percentage yield of nanosponges was determined by using formula percent yield = (practical yield of nanosponges/Theoretical yield of nanosponges) $x$ 100 . The percent yield of nanosponges can be determined by calculating initial weight of nanosponges and practical yield of nanosponges. ${ }^{15}$

\section{Determination of entrapment efficiency}

Nanosponge suspension was centrifuged then forms two parts i.e. supernatant and residue forms. Supernatant solution was selected and residue was separated by centrifugation at $2700 \mathrm{rpm}$ for $30 \mathrm{~min}$. The supernatant and residue was diluted by $0.1 \mathrm{~N} \mathrm{HCl}$. The concentration of cinnarizine in supernatant was determined spectrophotometrically (Jasco603) at 253nm. The entrapment efficiency was calculated through the formula $\%$ E.E = Entrapped drug/ (Entrapped drug + Drug in supernantant) x 100 .

\section{Determination of drug content}

Drug content was analyzed by taking $10 \mathrm{mg}$ of sample and dissolved in $100 \mathrm{ml}$ of $0.1 \mathrm{~N}$ hydrochloric acid. Each of solution was further diluted in $0.1 \mathrm{~N}$ hydrochloric acid. Solution was filtered to remove insoluble matter. Absorbance was measured by UV spectrophotometer at $253 \mathrm{~nm}^{16,17}$.

\section{Particle size analysis}

Particle size of prepared nanosponges was measured by particle size analyzer (NANOPOX, Symantec, Germany). Each sample was placed in transparent polystyrene cuvette (path length $=1 \mathrm{~cm}$ ) and placed in thermostatic sample chamber mean globule size and the span of resulting emulsion were determined by photon cross correlation spectroscopy (NANOPOX, Sympatec, Germany). Sample temperature was set at $25 \circ \mathrm{C}$ and runs of $60 \mathrm{~s}$ were performed. Detection was carried out a scattering angle of 90․ From the resulting correlation curves second order analysis was performed to calculate the mean globule size. The globule size distribution was expressed in term of span ${ }^{18,19}$.

\section{Polydispersity index}

Polydispersity index is measure of the heterogeneity of sizes of molecules or particles in a sample. A collection of objects was called uniform if the objects have the same size, shape, or mass. The data obtained from the particle size analysis using NANOPHOX instrument can be used to derive the polydispersity index of respective formulation by using following formula PDI $=\Delta \mathrm{d} /$ davg $^{19}$.

\section{Zeta potential}

The zeta of batches was measured by a Zeta sizer 2000 (Malvern Instrument UK). A sample was extemporaneously diluted in Milli-Q (Millipore Corp., USA) water $(1 \mu / 10 \mathrm{ml})$ and injected in the apparatus. The measurements were carried out in the fully automatic mode. Each sample was analyzed twice 20 .

\section{In vitro diffusion study}

Drug release from nanosponges was studied using a dialysis method. Dialysis bags were soaked before use in distilled water at room temperature for $12 \mathrm{hrs}$, followed by rinsing thoroughly in distilled water. In vitro release of cinnarizine from nanosponges was carried in dialysis sac $(12,000 \mathrm{MW}$ cut off; Sigma- Aldrich) with $150 \mathrm{ml}$ of $0.1 \mathrm{~N}$ hydrochloric acid at $37^{\circ} \mathrm{C}$. Two end of the dialysis sac were tightly bound with thread. The sac was hung inside a conical flask with the help of glass rod so that the portion of dialysis sac with the formulation dipped into $0.1 \mathrm{~N}$ hydrochloric acid. The beaker was kept on a magnetic stirrer (Matrex) and stirring was maintained at $100 \mathrm{rpm}$ at $37^{\circ} \mathrm{C}$ with a thermostatic control. Samples were collected at 5, 10, 15, 30, $45 \mathrm{~min}$ and then $1 \mathrm{hr}, 2 \mathrm{hr}, 3 \mathrm{hr}, 4 \mathrm{hr}$ and assayed spectrophotometrically for drug content at 253 $\mathrm{nm}$ and sample volume of $0.1 \mathrm{~N}$ hydrochloric acid maintained at the same temperature. The equal volume of fresh release medium was replaced at the same time intervals. The dissolution data analyzed for calculating the amount of drug released ${ }^{21,22 .}$

\section{In vivo pharmacodynamics study}

The protocol for the animal study in prescribed proforma was submitted to the Institutional Animal Ethics Committee (IAEC) of Modern College of Pharmacy, Nigdi, Pune. The protocol of animal study was approved by IAEC of Modern College of Pharmacy, Nigdi, Pune with approval no.MCP/IAEC/21/2016. The study was carried out on male albino wistar rats of weights $160-180 \mathrm{~g}$. The wistar rats were kept on fasting for $24 \mathrm{hrs}$ prior to dosing. The study 
of pharmacodynamics of CLN was carried out by using rat emesis model.

\section{Rat emesis model}

Male albino Wistar rats each weighing between 160 and $180 \mathrm{~g}$ are usually used in this study. In these animals which lack emetic reflex, pica (measured as kaolin intake) involves similar mechanisms as vomiting in humans and can be used to test the efficacy of anti-emetic drugs. It has been shown that pica is associated with $5-\mathrm{HT}$ release from the enterochromaffin cells, increased c-fos labelling in the area postrema and the nucleus tractus-solitarius, and delay in gastric emptying as with emesis in humans. In this experimental model, an oral dose $(40 \mathrm{mg} / \mathrm{kg})$ of copper sulfate was used for measuring pica in rats. Test sample (CLN suspension) is administered by oral route $10 \mathrm{~min}$ prior to emetic stimuli and pica was observed for a period of 120 hrs continuously ${ }^{22}$.

\section{Preparation of Kaolin pellet}

Gum Arabic (acacia) and hydrated aluminium silicate (kaolin) were mixed together (1:100 on a w/w basis) with distilled water to form a thick paste. Pellet of the resulting kaolin mixture were shaped to resemble the dimensions of the rats normal laboratory diet. The pellets were dried completely at room temperature ${ }^{23}$.

\section{In vivo pharmacokinetic study}

\section{Study design using Wistar albino rats}

The protocol for the animal study was approved by Institutional Animal Ethics Committee (IAEC) of Modern college of pharmacy, Nigdi, Pune as mentioned earlier. The study was carried out on male albino Wistar rats of weights 160-180g. The Wistar rats were kept on fasting for $24 \mathrm{hrs}$ prior to dosing. The rats were divided into two groups each containing six animals. Group A received Cinnarizine suspension in distilled water and Group B received nanosponges in distilled water. Two test groups were injected single dose of Cinnarizine equivalent $25 \mathrm{mg} / \mathrm{kg}$ given by oral route with the help of oral syringe. Blood samples were collected from the retro orbital plexus vein of each rat at time intervals of 1, 2, 3, 4 then 8, 12, 24, 36 (hrs) continuously. Blood samples were collected into heparinized tubes and RBCs were allowed to settle by centrifugation at $3000 \mathrm{rpm}$ for $30 \mathrm{~min}$. The supernatant plasma was collected in tube and analyzed by UV-visible spectrophotometer. The pharmacokinetic parameters for Cinnarizine following oral administration were determined from the plasma concentration- time data ${ }^{22,23}$.

\section{Preparation of stock solution}

Stock solution of Cinnarizine was freshly prepared in Acetronitrile to give a final concentration of $100 \mu \mathrm{g} / \mathrm{ml}$. Working solutions of Cinnarizine were prepared in Acetronitrile by appropriate dilution to give appropriate concentration of $2,4,6,8,10,12 \mu \mathrm{g} / \mathrm{mL}^{24}$.

\section{Extraction of rat plasma}

The blood samples of rat were obtained from its retro orbital plexus vein and collected in sodium EDTA tubes. These samples were centrifuged at $4500 \mathrm{rpm}$ for $30 \mathrm{~min}$. The plasma was separated by decanting it in other sodium EDTA tubes.

\section{Preparation of standard curve in rat plasma}

A standard curve was prepared by spiking $1 \mathrm{ml}$ plasma sample with $1 \mathrm{ml}$ of the working solution prepared above $2,4,6,8,10,12 \mu \mathrm{g} / \mathrm{mL}$ separately to produce calibration curve points equivalent to $1,2,3,4,5,6 \mu \mathrm{g} / \mathrm{mL}$ respectively . In each mixture, Acetronitrile added and vortexed for 2 $\mathrm{min}$ then centrifuged at $3000 \mathrm{rpm}$ for next $15 \mathrm{~min}$. The organic layer transferred to another tube and evaporated to dryness. The residue was reconstituted in $1 \mathrm{~mL}$ Acetronitrile and $20 \mu \mathrm{l}$ aliquot obtained.

\section{Extraction of sample}

Blood samples were collected at specific time interval into the tube containing disodium EDTA and centrifuged at 4500 for $10 \mathrm{~min}$. A $0.5 \mathrm{ml}$ of the resultant plasma sample was mixed with $1.0 \mathrm{~mL}$ of Acetronitrile added and vortexed for $2 \mathrm{~min}$ and then centrifuged at 3000rpm for next $3 \mathrm{~min}$. The organic layer transferred to another tube and evaporated to dryness. The residue reconstituted in $1 \mathrm{ml}$ of acetonitrile and $20 \mu \mathrm{l}$ aliquot was put into covette and at maximum wavelength of Cinnarizine observed the absorbance. The obtained results were used to determine for $C_{\max }, T_{\max }$, and Area Under curve $\left(A \cup C_{0-\infty}\right)$ measured by using linear and logarithmic trapezoid method ${ }^{25,26 .}$

\section{Stability study of nanosponges}

The stability study of Cinnarizine loaded nanosponges was carried out as per ICH guidelines. Samples maintained in a stability chamber under accelerated condition $\left(45^{\circ} \mathrm{C} \pm 2^{\circ} \mathrm{C}\right.$, $75^{\circ} \mathrm{C} \pm 5 \% \mathrm{RH}$ ) with humidity and temperature control, were taken at 0, 1, 2 and 3 month. Formulations were exposed to different thermal condition $45^{\circ} \mathrm{C} \pm 2{ }^{\circ} \mathrm{C}$. CLN was stored in air tight glass container. Relative humidity for a period of a month and drug behavior of formulation was tested by measuring the entrapment efficiency, particle size and zeta potential of nanosponges. Samples were centrifuged for $2000 \mathrm{rpm}$ for $30 \mathrm{~min}$ and measured the percent amount of drug entrapped in the nanosponges for periodic interval of one month. Total amount of the drug present in nanosponges was analyzed spectrophotometrically ${ }^{21,27}$.

\section{RESULTS}

\section{Preformulation study}

\section{UV spectrum analysis of Cinnarizine}

Calibration curve for Cinnarizine in $0.1 \mathrm{~N} \mathrm{HCl}$ was shown in Fig.no.1 $\left(R^{2}=0.999\right.$ and $\left.y=0.067 x+0.0173\right)$ 


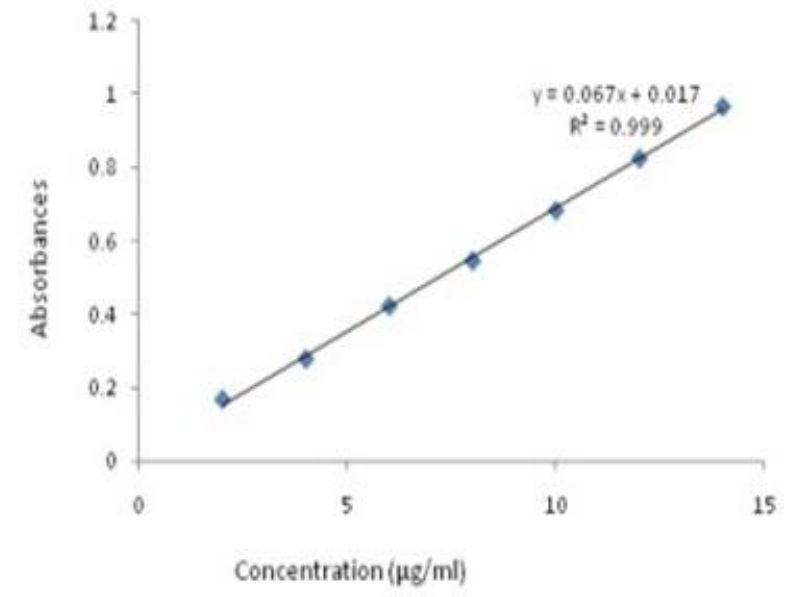

Figure 1: Calibration curve for Cinnarizine in $0.1 \mathrm{~N} \mathrm{HCl}$

\section{Drug polymer compatibility study}

FTIR spectrum showing chemical compatibility between Cinnarizine and Eudragit RS 100 is shown in Fig.no.2.

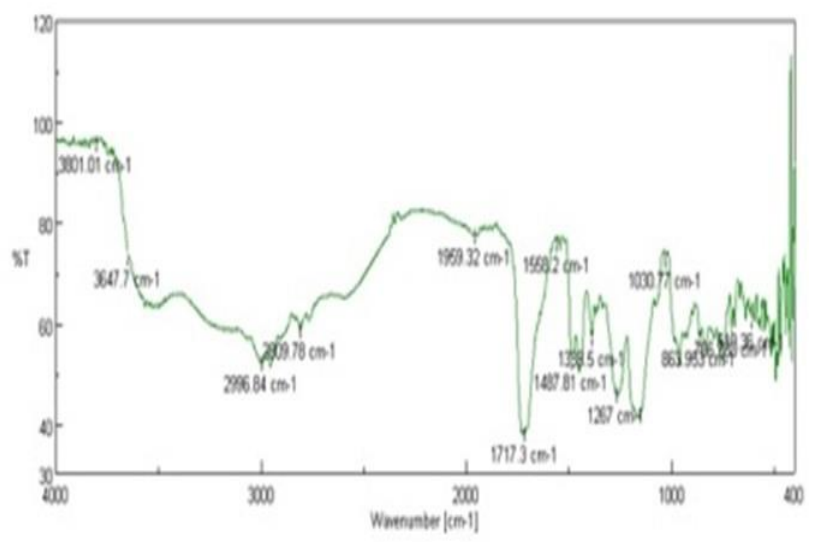

Figure 2: FTIR spectrum showing chemical compatibility between Cinnarizine and Eudragit RS 100

\section{Differential scanning calorimetry}

The DSC peak of cinnarizine was at $121^{\circ} \mathrm{C}$ which found to be slightly differing with standard i.e., within $118^{\circ} \mathrm{C}$ to $122^{\circ} \mathrm{C}$ shown in fig no.3 and DSC graph of Eudragit RS 100 and Optimized batch shown in fig.no.4 and fig. no 5 .

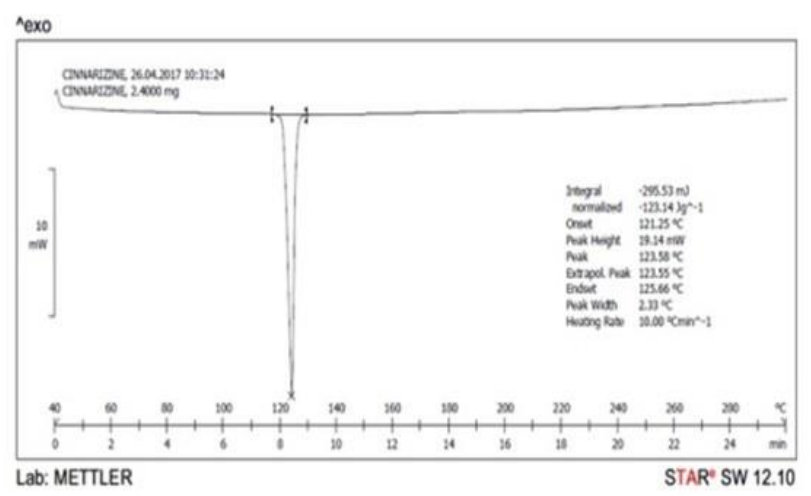

Figure 3: DSC peak of cinnarizine

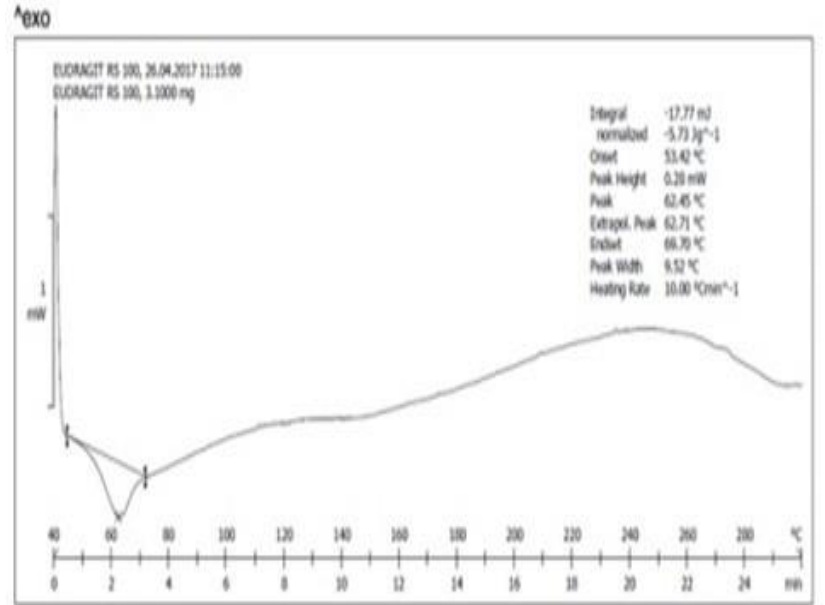

Lab: METTLER STAR' SW $12: 10$

Figure 4: DSC graph of Eudragit RS 100

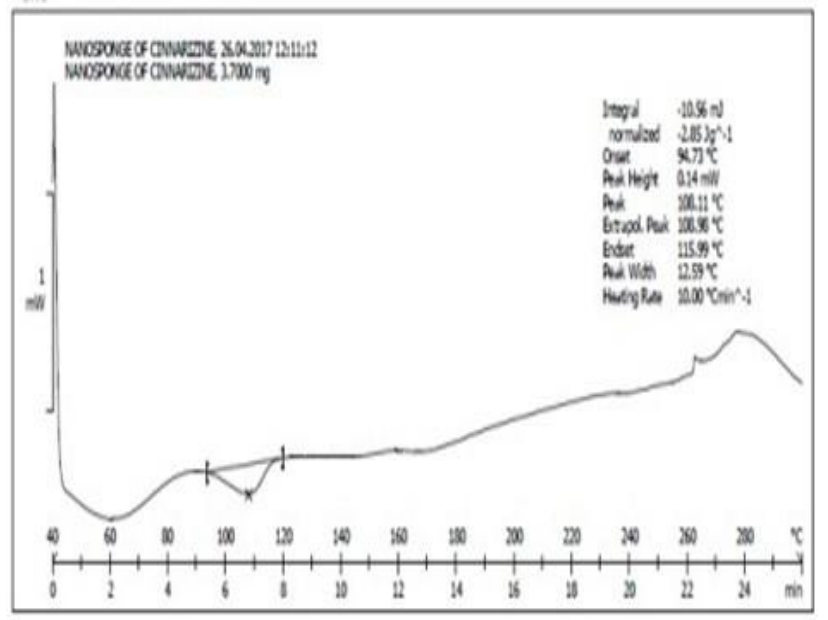

Figure 5: DSC graph of Optimized batch

\section{Powder X-ray diffraction studies (PXRD)}

The X-ray diffraction pattern of cinnarizine and Eudragit RS 100 suggests that it was amorphous powder shown in fig. no. 6 and fig. no.7.and Optimized batch (F5) PXRD shown in fig. no. 8

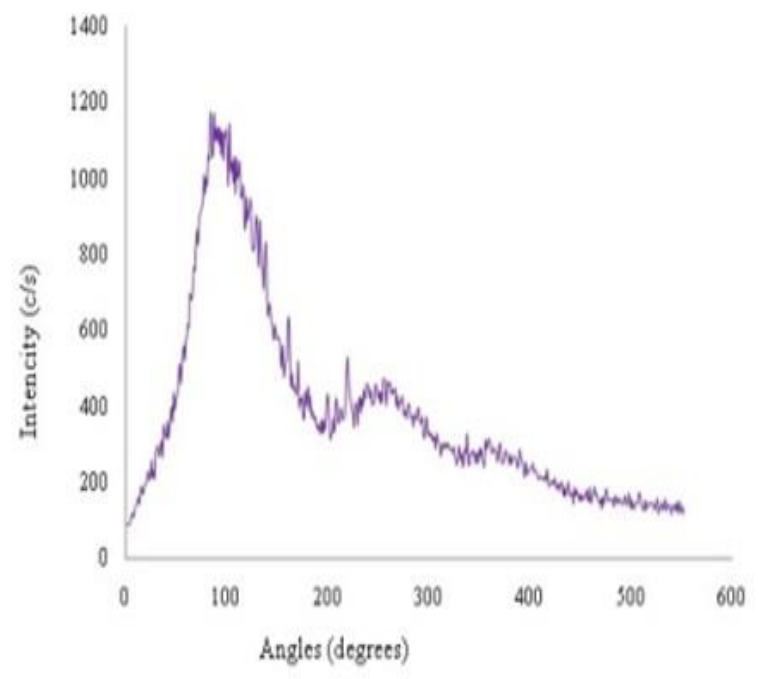

Figure 6: X-ray diffraction pattern of cinnarizine 


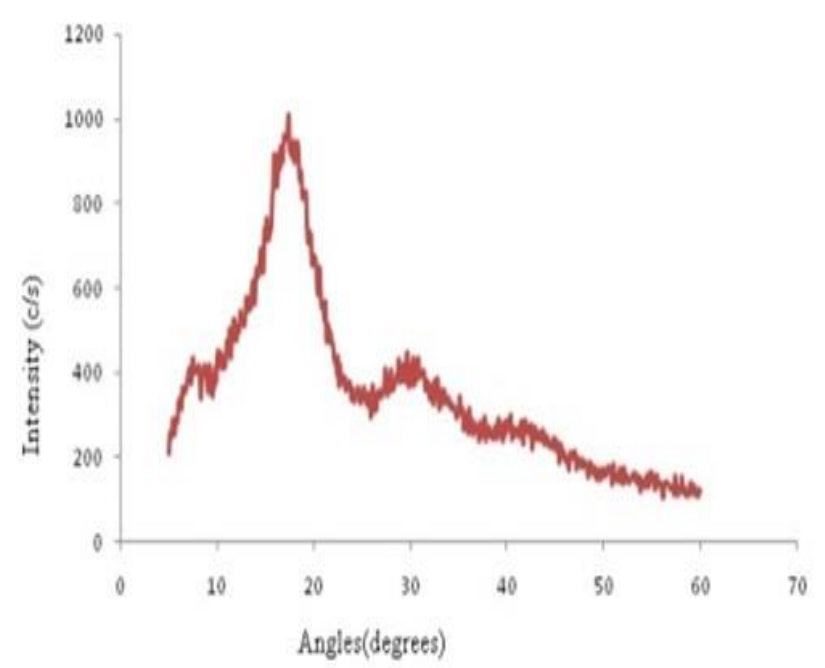

Figure 7: X-ray diffraction pattern of Eudragit RS 100

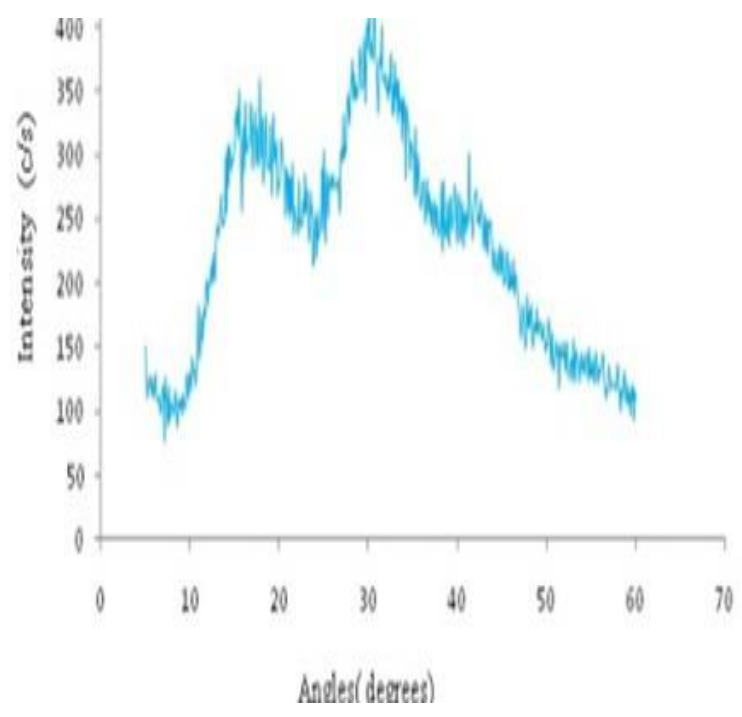

Figure 8: X-ray diffraction pattern of Optimized Batch

\section{Scanning electron microscopy (SEM)}

Scanning electron microscopy of cinnarizine, Eudragit RS 100 and Optimized batch (F5) were performed for study of surface morphology and topography shown in fig.no.9,10,11 respectively. CLN was found to be that discrete, spherical in shape.

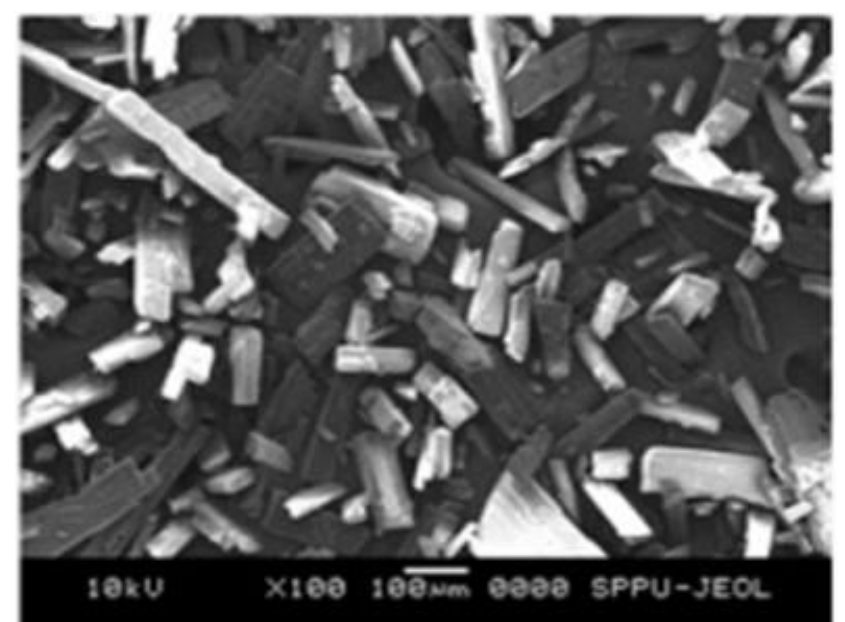

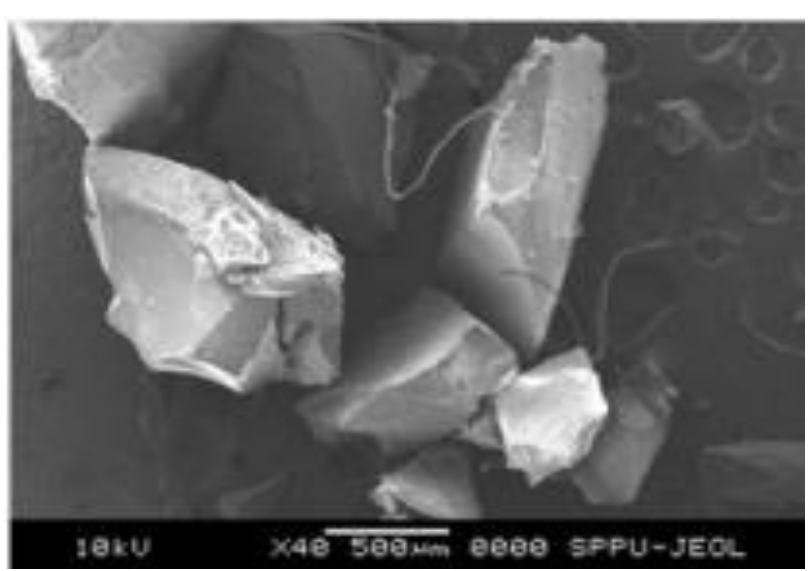

Figure 10: Scanning electron microscopy of Eudragit RS 100

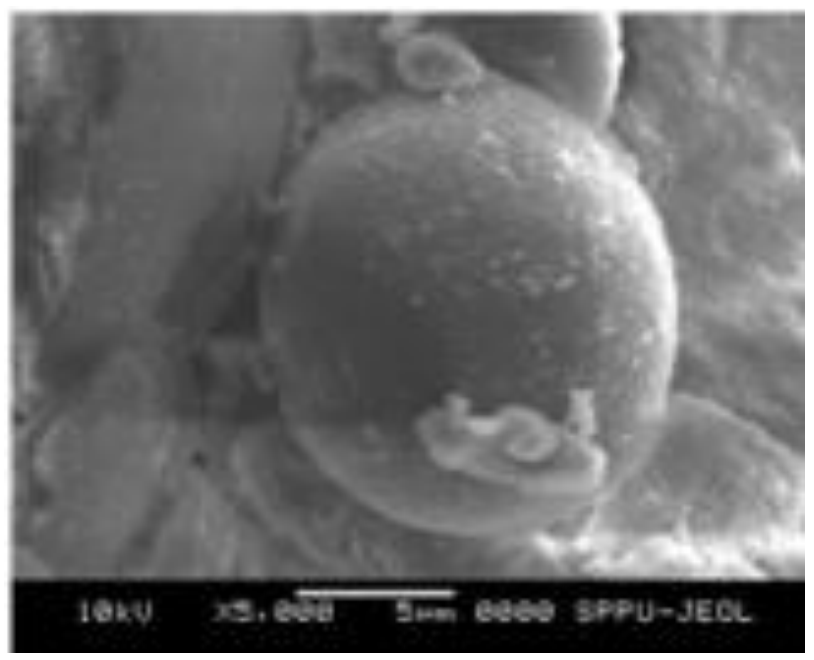

Figure 11: Scanning electron microscopy of Optimized batch (F5)

\section{Formulation study}

\section{Determination of percent yield}

Percent yield of nanosponges is shown in table no.2. The percent yield of nanosponges was in range of 50 to $72 \%$. Optimized batch (F5) percent yield was found to be $60.89 \pm 0.18 \%$.

\section{Determination of entrapment efficiency}

The entrapment efficiency of cinnarizine loaded nanosponge formulation is shown in table no.2. The entrapment efficiency of nanosponges was in range of 50 to $72 \%$. Optimized batch (F5) entrapment efficiency was found to be $60.89 \pm 0.18 \%$.

\section{Determination of drug content}

Drug content of F1 to F9 batches were found to be in range 50 to $82 \%$. The drug content of optimized batch (F5) was found to be $82.88 \pm 0.88 \%$. Drug content of F1 to F9 batches shown in table no.2

\section{Particle size analysis}

The particle size of F1 to F9 batches were found to be $100 \mathrm{~nm}$ to $500 \mathrm{~nm}$ shown in table no. 2

Figure 9: Scanning electron microscopy of cinnarizine

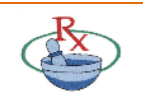


Table 2: Percent yield of nanosponges

\begin{tabular}{|c|c|c|c|c|c|c|}
\hline Batches & Yield (\%) & E.E. (\%) & Particle size (nm) & PDI & Zeta potential (mV) & Drug content (\%) \\
\hline F1 & $50.56 \pm 0.11$ & $78.69 \pm 0.24$ & 465.75 & $0.2775 \pm 0.01$ & 39.15 & $78.48 \pm 2.48$ \\
\hline F2 & $42.56 \pm 0.28$ & $78.54 \pm 0.22$ & 279.12 & $0.2413 \pm 0.02$ & 3.15 & $70.45 \pm 1.47$ \\
\hline F3 & $50.75 \pm 0.32$ & $74.32 \pm 0.25$ & 506.32 & $0.2709 \pm 0.08$ & 10.07 & $50.78 \pm 0.99$ \\
\hline F4 & $55.89 \pm 0.14$ & $69.97 \pm 0.37$ & 240.94 & $0.2436 \pm 0.01$ & 16.65 & $75.12 \pm 0.23$ \\
\hline F5 & $60.89 \pm 0.18$ & $70.85 \pm 0.41$ & 492.33 & $0.08103 \pm 0.04$ & 5.67 & $82.88 \pm 0.88$ \\
\hline F6 & $65.11 \pm 0.16$ & $80.88 \pm 0.39$ & 382.73 & $0.2886 \pm 0.02$ & 8.83 & $60.58 \pm 2.78$ \\
\hline F7 & $72.11 \pm 0.17$ & $72.11 \pm 0.22$ & 111.08 & $0.0971 \pm 0.06$ & 8.83 & $62.54 \pm 1.03$ \\
\hline F8 & $68.00 \pm 0.16$ & $78.81 \pm 0.14$ & 329.46 & $0.3544 \pm 0.01$ & 1.51 & $74.2 \pm 2.38$ \\
\hline F9 & $55.12 \pm 0.17$ & $82.36 \pm 0.34$ & 381.80 & $0.2462 \pm 0.05$ & 1.51 & $64.02 \pm 1.45$ \\
\hline
\end{tabular}

\section{Polydispersity index of nanosponges}

\section{In vitro diffusion study}

Polydispersity index of all batches was found to be less than one shown in table no.2

The release of drug from nanosponge using medium $0.1 \mathrm{~N}$ hydrochloric acid $(1.2 \mathrm{pH})$. The drug release of optimized

\section{Zeta potential}

batch F5 was found to be $97.65 \pm 2.15 \%$. (Table no.3)

Zeta potential of F1 to $\mathrm{F} 9$ in the range of 1.51 to $39.15 \mathrm{mV}$. The zeta potential value of optimized batch was found to be +5.67 .

Table 3: Drug release of optimized batch F5

\begin{tabular}{|c|c|c|c|c|c|c|c|c|c|c|}
$\begin{array}{c}\text { Time } \\
\text { (min) }\end{array}$ & $\mathbf{0}$ & $\mathbf{5}$ & $\mathbf{1 0}$ & $\mathbf{1 5}$ & $\mathbf{3 0}$ & $\mathbf{4 5}$ & $\mathbf{6 0}$ & $\mathbf{1 2 0}$ & $\mathbf{1 8 0}$ & $\mathbf{2 4 0}$ \\
\hline F1 & 0 & $12.18 \pm 0.55$ & $38.69 \pm 0.36$ & $49.52 \pm 1.23$ & $52.15 \pm 1.42$ & $58.56 \pm 0.56$ & $62.02 \pm 0.22$ & $65.59 \pm 0.69$ & $75.5 \pm 1.17$ & $76.86 \pm 1.24$ \\
\hline F2 & 0 & $16.06 \pm 0.41$ & $23.79 \pm 0.36$ & $43.26 \pm 0.98$ & $46.89 \pm 0.77$ & $47.78 \pm 0.78$ & $54.18 \pm 0.40$ & $57.59 \pm 0.53$ & $58.23 \pm 1.24$ & $60.88 \pm 1.56$ \\
\hline F3 & 0 & $14.33 \pm 0.32$ & $29.82 \pm 0.25$ & $35.87 \pm 0.78$ & $39.45 \pm 1.38$ & $43.57 \pm 1.01$ & $48.15 \pm 0.54$ & $52.98 \pm 0.37$ & $56.29 \pm 1.14$ & $58.63 \pm 1.06$ \\
\hline F4 & 0 & $8.1 \pm 074$ & $14.92 \pm 0.59$ & $43.45 \pm 0.69$ & $57.01 \pm 1.21$ & $57.15 \pm 0.64$ & $58.97 \pm 0.29$ & $62.19 \pm 0.80$ & $64.78 \pm$ & $66.54 \pm$ \\
\hline F5 & 0 & $20.28 \pm 0.85$ & $35.48 \pm 0.98$ & $45.99 \pm 1.67$ & $56.77 \pm 1.56$ & $65.45 \pm 0.78$ & $70.98 \pm 0.28$ & $83.09 \pm 0.76$ & $88.12 \pm 1.56$ & $97.65 \pm 2.15$ \\
\hline F6 & 0 & $16.35 \pm 0.63$ & $34.25 \pm 0.29$ & $48.63 \pm 1.46$ & $53.69 \pm 1.42$ & $64.52 \pm 0.64$ & $72.98 \pm 0.30$ & $75.98 \pm 0.63$ & $78.94 \pm 1.20$ & $80.45 \pm 1.56$ \\
\hline F7 & 0 & $19.34 \pm 0.26$ & $28.92 \pm 0.71$ & $35.62 \pm 0.87$ & $40.65 \pm 0.97$ & $51.89 \pm 0.46$ & $60.63 \pm 0.41$ & $68.34 \pm 0.53$ & $70.05 \pm 1.34$ & $75.25 \pm 1.34$ \\
\hline F8 & 0 & $17.56 \pm 0.62$ & $30.87 \pm 0.12$ & $40.98 \pm 0.85$ & $56.8 \pm 0.86$ & $60.08 \pm 0.82$ & $64.05 \pm 0.35$ & $67.08 \pm 0.61$ & $75.25 \pm 1.06$ & $78.98 \pm 1.57$ \\
\hline F9 & 0 & $18.59 \pm 0.57$ & $35.48 \pm 0.23$ & $42.31 \pm 1.24$ & $58.26 \pm 1.02$ & $62.02 \pm 0.65$ & $68.23 \pm 0.27$ & $70.12 \pm 0.58$ & $75.63 \pm 1.07$ & $81.21 \pm 1.26$ \\
\hline
\end{tabular}

\section{In vivo pharmacokinetic study}

Table 4: Concentration of CIS in rat plasma $(\mu \mathrm{g} / \mathrm{ml} / \mathrm{hr})$

\begin{tabular}{|c|c|c|c|}
\hline Sr. No. & Time(hrs) & \multicolumn{2}{|c|}{ Concentration of Cinnarizine } \\
\hline & & $\begin{array}{c}\text { Cinnarizine } \\
\text { suspension in } \\
\text { distilled water }\end{array}$ & $\begin{array}{c}\text { Cinnarizine } \\
\text { nanosponges in } \\
\text { distilled water }\end{array}$ \\
\hline 1 & 1 & 0.9594 & 1.1351 \\
\hline 2 & 2 & 3.7837 & 5.1621 \\
\hline 3 & 3 & 4.9324 & 6.4864 \\
\hline 4 & 4 & 5.4864 & 7.3243 \\
\hline 5 & 8 & 4.5810 & 6.987 \\
\hline 6 & 12 & 3.2432 & 4.7972 \\
\hline 7 & 24 & 1.5945 & 1.6789 \\
\hline 8 & 36 & 0.1216 & 0.098 \\
\hline
\end{tabular}

The result of pharmacokinetic parameters of cinnarizine suspension and cinnarizine nanosponge suspension has shown in table no.4, 5 and fig. No 12 and fig. no 13.

Table 5: Pharmacokinetic parameters

\begin{tabular}{|c|c|c|c|}
\hline Sr. No. & $\begin{array}{c}\text { Pharmacokinetic } \\
\text { parameters }\end{array}$ & $\begin{array}{c}\text { Cinnarizine } \\
\text { suspension } \\
\text { in distilled } \\
\text { water }\end{array}$ & $\begin{array}{c}\text { Cinnarizine } \\
\text { nanosponges } \\
\text { in distilled } \\
\text { water }\end{array}$ \\
\hline 1. & $\mathrm{C}_{\max }(\mu \mathrm{g} / \mathrm{ml})$ & 5 & 7 \\
\hline 2. & $\mathrm{~T}_{\max }(\mathrm{h})$ & 4 & 7 \\
\hline 3. & $\mathrm{AUC}(\mu \mathrm{g} / \mathrm{ml} / \mathrm{h})$ & 336.32 & 396.41 \\
\hline 4. & $\mathrm{~T}_{1 / 2}(\mathrm{~h})$ & 2 & 3.5 \\
\hline
\end{tabular}




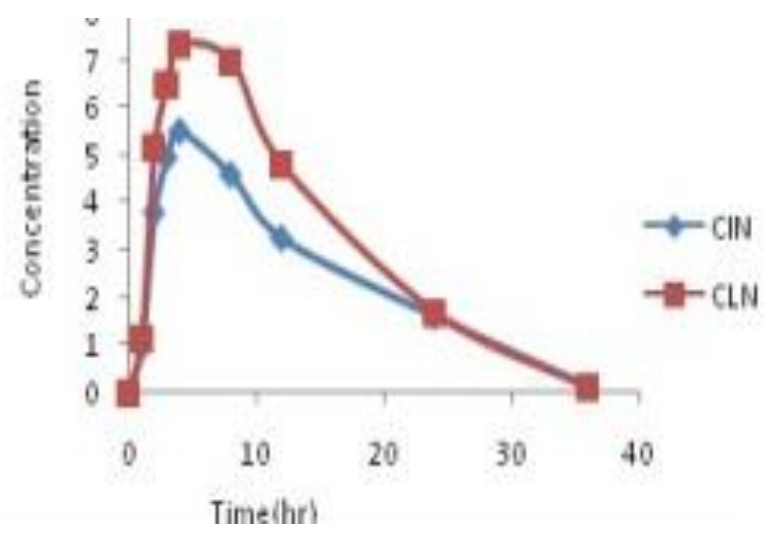

Figure 12: Pharmacokinetic parameters of cinnarizine suspension

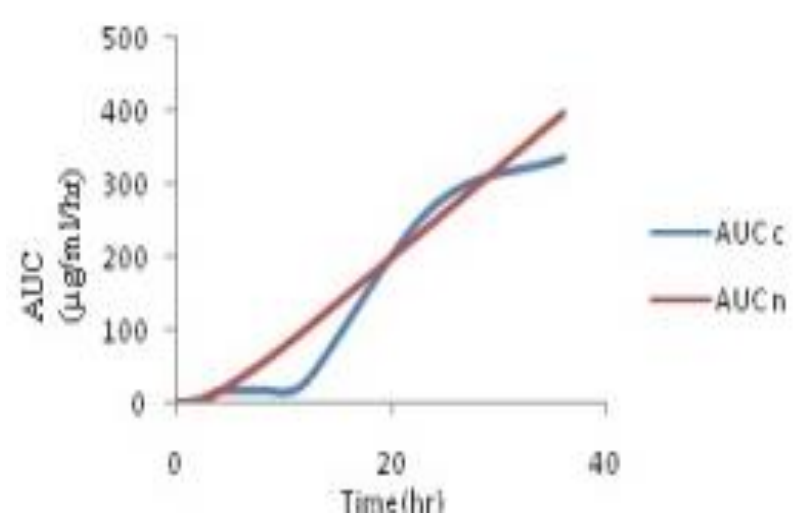

Figure 13: Pharmacokinetic parameters of cinnarizine nanosponge suspension

\section{In Vivo pharmacodynamic study}

After the five days observed that no vomiting occurred to albino wistar rat.

\section{Stability study of CLN}

Stability study optimized batch (F5) shown in table no.4

\begin{tabular}{|c|c|c|c|c|}
\hline Parameters & Batch F5 & & & \\
\hline Appearance & $\begin{array}{l}\text { White color } \\
\text { nanosponges }\end{array}$ & $\begin{array}{l}\text { White color } \\
\text { nanosponges }\end{array}$ & $\begin{array}{l}\text { White color } \\
\text { nanosponges }\end{array}$ & $\begin{array}{l}\text { White color } \\
\text { nanosponges }\end{array}$ \\
\hline E.E. (\%) & $70.85 \pm 0.41$ & $70.71 \pm 2.1$ & $70.59 \pm 1.8$ & $70.7 \pm 1.75$ \\
\hline Particle size(nm) & 492.33 & $500-550$ & $500-550$ & $500-550$ \\
\hline Zeta potential(mV) & 5.67 & 6.70 & 6.87 & 6.98 \\
\hline
\end{tabular}

\section{DISCUSSION}

\section{Preformulation study}

\section{U.V spectrum analysis of Cinnarizine}

From calibration curve it can concluded that it follows Beer's Lambert's law and thus gives linear equation of coefficient of correlation equal to 0.999 .

\section{Drug -polymer compatibility}

Chemical compatibility between Cinnarizine and Eudragit RS 100 is shown in fig.no.3. Physical mixture shown two prominent peaks of piperazine and alkene group shown there is no incompatibility between the ingredients.

\section{Differential scanning calorimetry}

Cinnarizine has shown a prominent peak at $123^{\circ} \mathrm{C}$ due to slight change in concentration.

\section{Powder X-ray diffraction study}

The X-ray diffraction pattern of cinnarizine suggests that it is an amorphous powder. FTIR spectra of cinnarizine have given the idea about amorphous nature of cinnarizine due to $3066 \mathrm{~cm}^{1}$ stretch. PXRD study pattern of Eudragit RS 100 also showed amorphous nature.

\section{Scanning Electron Microscopy}

It was observed by SEM analysis that nanosponges were uniform spherical in shape.

\section{Formulation study}

\section{Determination of percentage yield}

It was noted that at higher stirring rate the production yield decreased and also polymer adhered to magnetic bead due to turbulence created within the external phase and hence production yield decreased.

\section{Determination of entrapment efficiency}

The E.E. was affected by internal phase and external phase ratio. The E.E. changed when drug and polymer ratio change. The highest loading efficiency was found for the F9 formulation where a greater amount of drug was encapsulated .Percentage entrapment depends on internal phase and external phase volume .It suggests that change in phase volume changed the entrapment efficiency.

\section{Determination of drug content}

The effect of drug: polymer ratio on the physical characteristics of the formulated nanosponges was examined for various drugs: polymer ratio of nanosponge 
at stirring speed of $2000 \mathrm{rpm}$ for $3 \mathrm{hrs}$. It was observed that as drug: polymer ratio increases, the particle size decreased. This is probably due to the fact that at higher relative drug content, the amount of polymer available per nanosponge to encapsulate the drug becomes less, thus reducing the thickness of the polymer wall and hence smaller nanosponges.

\section{Particle size analysis}

Particle size of CLN was found to be below 500nm due to nanosize the surface area was significantly increase and it greatly increases rate of solubilization. An added benefit was that time taken by nanosponge system to traverse the small and large intestine was significantly increased thus maximizing the amount of drug that was absorbed. The author Dr. Prathima Srinivas et al studied were found to be volume of internal phase increased particle size in the polymers did not follow any particular pattern due to decreased viscosity of internal phase. Preparation of cinnarizine loaded nanosponges used $10 \mathrm{ml}$ of dichloromethane therefore decreases viscosity of internal phase and formed appropriately sized nanosponges.

\section{Polydispersity index of nanosponge}

Polydispersity index of all batches was found to be less than 0.7 . Thus, the particle size distribution sample was found to mid-range polydispers.

\section{Zeta potential of nanosponge}

The zeta potential value of optimized batch (F5) was +5.67 $\mathrm{mV}$. The absolute value of zeta potential was lower than those values reported in the literature. This might be attributed to sorbitan monooleate, a nonionic surfactant which decreases the electrostatic repulsion between the particles and sterically stabilizes the nanosponge by forming a coat around their surface. The positive charge of cinnarizine loaded nanosponges may be attributed from cationic poly (meth) acrylates, viz. Eudragit RS 100, having quaternary ammonium group.

\section{In vitro diffusion study}

According to in vitro drug release study maximum time required to release drug $(\mathrm{Cl})$ was found to be $4 \mathrm{hrs}$.

\section{In Vivo pharmacokinetic study}

Cinnarizine suspension in distilled water was found to be $C_{\max } 5 \mu \mathrm{g} / \mathrm{ml}$ in time "i.e."; $T_{\max } 4$ of hrs suggesting the rapidly absorbed from gastrointestinal tract, with an absorption window in upper gastrointestinal tract. Whereas the $C L N$ in which $\mathrm{C}_{\max }$ of about $7 \mu \mathrm{g} / \mathrm{ml}$ in time i.e., $T_{\max } 7$ of hrs shown that delayed onset of action. This may indicate that plain cinnarizine was dominantly absorbed from stomach. Poor water solubility of cinnarizine its absorption resulting in lesser $\mathrm{C}_{\max }$ but in case of cinnarizine nanosponges suspension it may due to its absorption from gastrointestinal tract and nanosponges approach improved solubility of cinnarizine resulting into better absorption i.e. $\mathrm{C}_{\max }$ of additionally the increases in AUC shows the increased exposure of the drug to the body after encapsulating pure drug in the nanosponges. Thus it is consider that there may be changes to increases bioavailability of the drug after using nanosponges approach.

\section{In vivo pharmacodynamic study}

Pharmacodynamics study of cinnarizine loaded nanosponges with the help of rat emesis model explain in experimental work. Test samples are administered by oral route $10 \mathrm{~min}$ prior to emetic stimuli and pica is observed for a period of $120 \mathrm{hrs}$. After five days observation found that no vomiting occurred to albino wistar rat. It shows that cinnarizine loaded nanosponges shows the antiemetic activities.

\section{Stability study of CLN}

The effect of the accelerated testing was carried out for the formulation under storage i.e. F5 (optimized batch) for 3 months. There was no significance difference found between initial drug entrapment, drug content, particle size and zeta potential for the formulation after storage for 3 months.

\section{CONCLUSION}

It was possible to prepare nanosponges of cinnarizine by using quasi emulsion solvent diffusion method to obtain best possible formulation. According to in vitro study, maximum drug release $(97.65 \pm 2.15 \%)$ was found in optimized batch (F5). In vivo pharmacokinetic study showed that $C_{\max }$ of cinnarizine loaded nanosponge is 1.4 times more than cinnarizine suspension. $T_{\max }$ of cinnarizine loaded nanosponge is 1.7 times more than cinnarizine suspension. AUC of cinnarizine loaded nanosponge is 1.1 times more than cinnarizine suspension. Cinnarizine loaded nanosponge increases efficacy of cinnarizine. According to in vivo pharmacodynamic study Cinnarizine loaded nanosponge show antiemetic activity.

\section{REFERENCES}

1. Raghuvanshi S, Kamla P. Recent advances in Delivery systems and Therapeutics of cinnarizine: A Poorly Water Soluble Drug with Absorption Window In stomach .J Drug deliv 14, 2014, 1 16.

2. Eldose A, Twinkle P, Honey S, Patel J, Twinkle Z, Hitesh J, Upadhyay U. Nanosponges: A Novel Nano Drug Carrier. JIAATS 9, 2015, 1-7.

3. Vishwakarma A, Nikam P, Mogal R, Talele S. Review On Nanosponges: Benefication for Novel Drug Delivery. Int J of Pharm Tech Res 6, 2014, 11-20.

4. Gursalkar T, Bajaj A, Jain D. Cyclodextrin based nanosponges for pharmaceutical use: A review, Acta Pharm 63, 2013, 335358.

5. Shringirish M, Prajapati S, Mahor A, Alok S, Yadav P, Verma A. Nanosponges: a potential nanocarrier for novel drug deliverya review. Asian Pac J of Trop Dis 4, 2014, S519-S526.

6. Patil S, Mohite S. Formulation, Design and Development of Artesunate Nanosponges.ejpmr 5, 2016, 206-211. 
7. Patnaik A, Mantry S. Formulation and Evaluation of Gastroretentive floating microsphere of cinnarizine. Asian Journal of Pharmaceutical and Clinical Research 5, 2012, 100109.

8. Harsulkar A, Sreenivas S. Design and development of bioadhesive multiparticule drug delivery system. International Journal of Pharmaceutical Innovation 8, 2013, 84-93.

9. Chen H, Khemtong C, Yang X, Chang, Gao J. Nanonization strategies for poorly water-soluble drugs. Drug discovery today 7, 2011, 354-360.

10. Tamkhane V, Sharma P. Nanosponge-A novel drug delivery System, Journal of Current Pharma Research, 2014, 11861193.

11. Raja C, Kiran G, Anusha K. Fabrication and Evaluation of ciprofloxacin loaded nanosponges for Sustained release, International Journal of Research in Pharmaceutical and Nano Sciences, 2013, 1-9.

12. Subramanian S, Singireddy A, Krishnamoorthy K, Rajappan M. Nanosponges: A Novel Class of Drug Delivery System review, Journal Pharmacy Pharmaceutical Sciences, 2012, 203-211.

13. Rajeshree $M$, Harsha $P$, Vishnu $P$, Photostability enhancement of miconazole nitrate by microsponge formulation, International Journal of current Tread in Pharmaceutical research 2014, 337-358.

14. Francesco T, Marco Z, Roberta C. Cyclodextrin-based nanosponges as drug carriers. Beilstein Journal of Organic Chemistry vol. 8, 2012, 2091-2099.

15. Subramanian S, Anandam S, Kannan K, Manavalan R. Nanosponges: a novel class of drug delivery system .Journal of pharmaceutical Sciences 2011, 203-211.

16. Srinivas P, Sreeja K. International journal of drug development and research. Formulation and evaluation of voriconazole loaded nanosponges for oral and topical drug delivery 1, 2013, 55-69.

17. Barkai A, Pathak V, Benita S. Polyacrylate (Eudragit retard) microspheres for oral controlled release of nifedipine, Formulation design and process optimization. Drug Dev Ind Pharm, 1990, 16, 2057-2075.

18. Bhise S, Mathure D, Mithun V, Patil V, Patankar R. Solubility enhancement of antihypertensive agent by solid dispersion technique: International journal of pharmacy \& life sciences 8, 2011, 970-975.

19. Shankar S, Vavia P, Francesco T, Satyen T. Formulation of betacyclodextrin based nanosponges of itraconazole Journal of inclusion phenomenon of macrocyclic chemistry 57, 2007, 89-94.

20. Penjuri S, Ravoura N, Bns S, Poreddy S. Formulation and evaluation of Lansoprazole loaded nanosponges. Turk J Pharm Sci 13, 2016, 304-310.

21. Khalid A, Ansari R, Francesco T, Roberta C.Cyclodextrin-based nanosponges for delivery of resveratrol: in vitro characterization, stability, cytotoxicity and permeation study .American association of pharmacy scientist 12, 2013, 279286.

22. Kostewicz E, Wunderlich $M$, Brauns $U$, Becker R, Bock $T$, Dressman $B$, Prediction of precipitation of poorly soluble weak bases upon entry in the small intestine, Journal of pharmaceutics and Pharmacology 56, 2004, 43-51.

23. Rudda J, Yamamotob K, Yamatodanib A, Takeda N. Differential action of ondansetron and dexamethasone to modify cisplatin-induced acute and delayed kaolin consumption in rats. European Journal of Pharmacology 4, 2002, 47-52.

24. Naga M, Kumar S. Validated RP-HPLC method for simultaneous estimation of cinnarizine and domperidone in bulk and pharmaceutical dosage form. Journal of Pharmaceutical and Scientific Innovation 2, 2013, 46-50.

25. Brahmankar D, Jaiswal S. Biopharmaceutics and pharmacokinetic-A Treatise, 2nd edition, M. K. Jain for Vallabh prakashan 2009, 235-239.

26. Khalid A, Pradeep R, Francesco T, Roberta C. Cyclodextrinbased nanosponges for delivery of resveratrol: in vitro characterisation, stability, cytotoxicity and permeation study, American association of pharmaceutical scientists 4, 2013, 279-286.

27. Mishra K, Shikhri M,Sharma R and Goojar M. Optimization, formulation development and characterization of Eudragit RS 100 loaded microsponges and subsequent colonic delivery, International Journal of Drug Discovery And Herbal Research vol.1, 2011, 8-13.

28. Jilsha G, Viswanad V. Nanosponges: a novel approach of drug delivery System. International journal of pharmaceutical sciences and research 19, 2013, 219-223.

29. Pund S, Pawar S, Gangurde S, Divate D. Ttranscutaneous delivery of leflunomide nanoemulgel: mechanistic investigation into physicochemical characteristics, in vitro anti-psoriatic and anti-melanoma activity. International Journal of Pharmaceutics 14805, 2015, 1-9.

30. Ahmed S, Hasan M , Sheemul H, Ahmed S, Mahmood Z, Azhar I, Habtemariam S, Anti-emetic effects of bioactive natural products .Phytopharmacology 15, 2013, 390-433.

Source of Support: None declared.

Conflict of Interest: None declared.

For any question relates to this article, please reach us at: editor@globalresearchonline.net New manuscripts for publication can be submitted at: submit@globalresearchonline.net and submit_ijpsrr@rediffmail.com 